\title{
VWF/ADAMTS13 AND Ischemic Stroke
}

\author{
Wei Liu and Benshu Zhang* \\ Department of Neurology, Tianjin Medical University General Hospital, China
}

*Corresponding author: Benshu Zhang, Department of Neurology, Tianjin Medical University General Hospital, China

\begin{tabular}{|c|c|}
\hline ARTICLE INFO & ABSTRACT \\
\hline Received: 幽 May 21, 2019 & Citation: Wei Liu, Benshu Z. VWF/ADAMTS13 AND Ischemic Stroke. Biomed J Sci \& Tech \\
\hline Published: 㸷 May 24, 2019 & Res 18(2)-2019. BJSTR. MS.ID.003134. \\
\hline
\end{tabular}

\section{Introduction}

In recent years, more and more attention has been paid to the study of Von Willebrand factor (VWF) in ischemic stroke. The risk factors of atherosclerosis, such as smoking, obesity, hyperlipidemia, diabetes mellitus, hypertension and metabolic syndrome, can lead to the increase of VWF. The unique pathological process of atherosclerosis is:

a) Activation of endothelial cells and white blood cells

b) Platelet overreaction

c) Hypercoagulable state

d) Increase of fibrinogen level

e) Decrease of fibro lytic activity.

Among them, endothelial cell injury is the most prominent. VWF is the most widely used biomarker for endothelial cell injury. When atherosclerotic plaques are ruptured and vascular endothelial cells are injured, VWF participates in the hemostatic process by binding platelets to form thrombus and by preventing coagulation factor VIII (F VIII) from being hydrolyzed by protease [1]. When plasma ADAMTS13 level decreased, increased VWF can enhance the risk of ischemic stroke [2].

\section{VWF and ADAMTS13}

VWF is a large glycoprotein polymer with adhesion function, which is synthesized and secreted by endothelial cells and megakaryocytes. VWF is stored in platelet $\alpha$-granules and endothelial Weibel-Palade bodies, and is then released into circulating blood. In plasma, it first binds each other by C-terminal cross-linking disulfide bond, hen forms polymer by the $\mathrm{N}$-terminal disulfide bond and exists as mixed polymers [3]. Normally, once the highly active
Ultra Large von Willebrand factor (ULVWF) is released into the plasma, it will be digested by plasma metalloprotease ADAMTS13 (A Disinterring and Metalloproteinase with Thrombospondin motif repeats 13) between the Tyr842 and the Met843 in the A2 domain into smaller and less active VWF, which is less easily to form thrombus, and binding platelets only when the regulator appeared, the cleavage activity increased, and under adhesion state. The role of ADAMTS13 in TTP can explain its importance very well. In TTP patients, ULVWF cannot be hydrolyzed due to the deficiency or decreased activity of ADAMTS13, which results in extensive microvascular thrombus and consumptive thrombocytopenic purpura. The thrombus is composed of a large number of VWF and platelets. ADAMTS13 only binds to VWF specifically, decomposes VWF polymer into lower activity and less thrombus-forming polymer, so it has the effect of anti-VWF mediated thrombosis [4]. Usually, when newly released into the blood, ULVWF first attaches to the endothelial surface through P-selectin and binds platelets by forming strands with other molecules. ULVWF becomes very heavy after adhering to platelets, when drafted by the sheer force and torsional force from strong blood flow, the binding sites of $\mathrm{A} 1$ and A3 domains to ADAMTS13 will be exposed [5]. The A2 domain is not involved in the binding process, which is due to the change of spatial structure after platelet binding to ULVWF and the change of capture speed between ADAMTS13 and ULVWF at high velocity. The hydrolysis of ULVWF is related to endothelial adhesion, shear force and ADAMTS13 capture rate, therefore, there are VWF polymers of different sizes in plasma, rather than VWF with the same structure. When ADAMTS13 is deficient, uncut ULVWF that fixed on the surface of endothelial cells can bind platelets quickly, which can recruit more platelets and leukocytes under high shear force [6]. Under high shear force, the uncut ULVWF can be released into 
plasma, which aggregates platelets to form thrombus and blocks distal blood vessels, this theory has been confirmed in animal experiments and in vitro models [7].

\section{Association Between VWF/ADAMTS13 and Acute Ischemic Stroke}

When plasma ADAMTS13 level decreased, increased VWF can enhance the risk of ischemic stroke [8]. In the early stage of acute ischemic stroke ( $\leq 4$ weeks), VWF increased significantly and the ADAMTS13 level decreased. These studies suggest that acute ischemic stroke is closely associated with VWF/ADAMTS13. With the deepening of the study, the researchers found that in the middle cerebral artery occlusion model, the infarction area of $\mathrm{VWF}^{-/}$mice was significantly lower than that of wild type mice by nearly $50 \%$. Meanwhile, the infusion of recombinant human ADAMTS13 into the middle cerebral artery stroke model of wild type mice also reduced the infarction area of mice and did not cause bleeding [9]. The increase of plasma VWF and FVIII in patients with acute ischemic stroke indicated an increased risk of complications and severe neurological deficit [10]. Population based Rotterdam found that increased VWF level and decreased ADAMTS13 level could increase mortality in patients with acute myocardial infarction [11]. In vivo studies we have found that ADAMT13 can reduce the permeability of blood-brain barrier and inhibit inflammatory reaction in intracerebral hemorrhage, which is achieved by its proteolysis of VWF [12]. These direct or indirect studies show that VWF not only participates in the coagulation process, plays an important role in thrombosis, but also mediates inflammatory response, adjusts vascular permeability and aggravates the development of the disease. VWF provides a good target for the prevention and treatment of ischemic stroke.

\section{VWF and t-PA-Resistant Occlusions in Acute Ischemic Stroke}

Less than half of the patients who received t-PA benefit from it, and the recanalization rate of intravenous t-PA is low, indicating the existence of t-PA-resistant occlusions; however, the cause of this resistance is still unclear. Denorme et al. not only found that the thrombus from patients with acute ischemic stroke contained 10.1\%-20.3\% VWF, but also established the middle cerebral artery occlusion model of ADAMTS13-/- mice, and further confirmed that t-PA could not dissolve fibrin thrombus rich in VWF, which could be rapidly cleaved by recombinant ADAMTS13 [13]. However, another study found that VWF-platelet complex induced by endothelial cell injury in TTP model could be dissolved by streptokinase and its catalytic product plasmin, and the mechanism of endothelial cell injury in ischemic stroke might be different, and therefore the thrombosis might be also different [14].

\section{Conclusion}

VWF/ADAMTS13 is closely associated with acute ischemic stroke. Fibrin combined with VWF in acute ischemic stroke induced by arteriosclerosis thrombosis may resist the thrombolysis effect of $\mathrm{t}$-PA, and the recanalization rate of blood vessels is low. Due to its hydrolysis of VWF, ADAMTS13 can be used as a new method for the treatment of acute ischemic stroke.

\section{References}

1. De Meyer SF, Stoll G, Wagner DD, Kleinschnitz C (2012) von Willebrand factor: an emerging target in stroke therapy. Stroke a journal of cerebral circulation 43(2): 599-606.

2. Sonneveld MA, de Maat MP, Portegies ML, Kavousi M, Hofman A, et al. (2015) Low ADAMTS13 activity is associated with an increased risk of ischemic stroke. Blood 126(25): 2739-2746.

3. Lenting PJ, Christophe OD, Denis CV (2015) von Willebrand factor biosynthesis, secretion, and clearance: connecting the far ends. Blood 125(13): 2019-2028

4. Han MouTsai (2010) Pathophysiology of thrombotic thrombocytopenic purpura. Int J Hematol 91(1): 1-19.

5. Wijeratne SS, Li J, Yeh HC, Nolasco L, Zhou Z, et al. (2016) Singlemolecule force measurements of the polymerizing dimeric subunit of von Willebrand factor. Phys Rev E 93(1): 012410

6. Bernardo A, Ball C, Nolasco L, Choi H, Moake JL, et al. (2005) Platelets adhered to endothelial cell-bound ultra-large von Willebrand factor strings support leukocyte tethering and rolling under high shear stress. J Thromb Haemost 3(3): 562-570.

7. Chauhan AK, Motto DG, Lamb CB, Bergmeier W, Dockal M, et al. (2006) Systemic antithrombotic effects of ADAMTS13. J Exp Med 203(3): 767776 .

8. Sonneveld MA, de Maat MP, Portegies ML, Kavousi M, Hofman A, et al. (2015) Low ADAMTS13 activity is associated with an increased risk of ischemic stroke. Blood 126(25): 2739-2746.

9. Zhao BQ, Chauhan AK, Canault M, Patten IS, Yang JJ, et al. (2009) von Willebrand factor-cleaving protease ADAMTS13 reduces ischemic brain injury in experimental stroke. Blood 114(15): 3329-3334.

10. Samai A, Monlezun D, Shaban A, George A, Dowell L, et al. (2014) Von Willebrand factor drives the association between elevated factor VIII and poor outcomes in patients with ischemic stroke. Stroke; a journal of cerebral circulation 45: 2789-2791.

11. MA Franco OH, Ikram MA, Hofman A, Kavousi M, de Maat MP, et al. (2016) Von Willebrand Factor, ADAMTS13, and the Risk of Mortality: The Rotterdam Study. Arterioscler Thromb Vasc Biol 36(12): 2446-2451.

12. Cai P, Luo H, Xu H, Zhu X, Xu W,et al. (2015) Recombinant ADAMTS 13 Attenuates Brain Injury After Intracerebral Hemorrhage. Stroke 46(9): 2647-2653.

13. Denorme F, Langhauser F, Desender L, Vandenbulcke A, Rottensteiner H,Plaimauer B, et al. (2016) ADAMTS13-mediated thrombolysis of t-PAresistant occlusions in ischemic stroke in mice. Blood 127(19): 2337 2345

14.Dong JF (2016) Dissecting stroke for anti-VWF therapeutics. Blood 127(19):2271-2272. 


\section{ISSN: 2574-1241}

DOI: 10.26717/BJSTR.2019.18.003134

Benshu Zhang. Biomed J Sci \& Tech Res

(c) (i) This work is licensed under Creative

Submission Link: https://biomedres.us/submit-manuscript.php

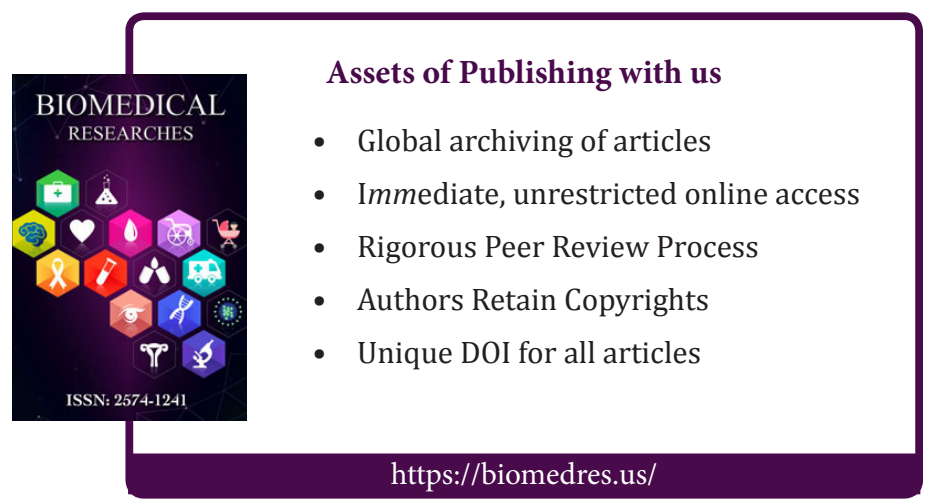

